\title{
Unilateral surgical maxillary expansion with palatal distractor allowing traction of impacted canine
}

\author{
- Ricardo Pimenta D’Avila Department of Oral and Maxillofacial Surgery, Prosthesis and Traumatology, School of Dentistry, University \\ of São Paulo, São Paulo, SP, Brazil • Lilian Victoria Perez Espinola Department of Oral and Maxillofacial Surgery, Prosthesis and \\ Traumatology, School of Dentistry, University of São Paulo, São Paulo, SP, Brazil Alessandro Costa da Silva Department of \\ Oral and Maxillofacial Surgery of Santa Catarina Hospital, São Paulo, SP, Brazil • João Gualberto C. Luz Department of Oral and \\ Maxillofacial Surgery, Prosthesis and Traumatology, School of Dentistry, University of São Paulo, São Paulo, SP, Brazil
}

ABSTRACT | Objectives: Bone-to-bone or palatal distractor has as the main advantage the fact that mechanical forces act directly on the bone in the desired area, thereby avoiding dental inclinations or undesirable movements of the maxillary segments, as well as causing no damage to the periodontium. The aim of this study is to present a case report of treatment for unilateral maxillary discrepancy associated with the presence of an impacted maxillary left canine with this type of device. Methods: A 23-year-old man was diagnosed with unilateral maxillary discrepancy associated with an impacted maxillary left canine. He was treated using unilateral subtotal LeFort I osteotomy with a palatal distractor tool associated with traction of the impacted maxillary left canine. Results: The results obtained were satisfactory and the desired amount of unilateral transverse skeletal correction was achieved without any complications. Conclusion: The authors could conclude that unilateral surgically assisted maxillary expansion with the aid of palatal distractor was efficient and promoted good occlusion with reduced morbidity.

DESCRIPTORS || Palatal Expansion Technique; Orthognathic Surgery; Cuspid; Abnormalities.

RESUMO | Expansão cirúrgica unilateral da maxila com distrator palatal possibilitando tracionamento de canino impactado • Objetivos: O uso de distrator ósseo ou palatal tem como principal vantagem o fato de as forças mecânicas atuarem diretamente sobre o osso na área desejada, evitando assim inclinações dentárias ou movimentos indesejáveis dos segmentos maxilares, bem como não causando danos ao periodonto. O objetivo deste estudo é apresentar um relato de caso sobre o tratamento para discrepância unilateral da maxila associada a canino maxilar esquerdo impactado com esse tipo de instrumento. Métodos: Um homem de 23 anos foi diagnosticado com discrepância maxilar unilateral associada a canino maxilar esquerdo impactado e foi tratado com osteotomia LeFort I unilateral subtotal e uso de um distrator palatal associado com tração do canino maxilar esquerdo impactado. Resultados: Os resultados obtidos foram satisfatórios e a quantidade desejada de correção esquelética transversal unilateral foi alcançada sem nenhuma complicação. Conclusão: Os autores puderam concluir que expansão cirúrgica unilateral da maxila com a ajuda de distrator palatal mostrou-se eficiente e promoveu boa oclusão com morbidade reduzida.

DESCRITORES | Técnica de Expansão Palatina; Cirurgia Ortognática; Dente Canino; Anormalidades.

CORRESPONDING AUTHOR | • João Gualberto C. Luz Department of Oral and Maxillofacial Surgery, Prosthesis and Traumatology, School of Dentistry, University of São Paulo • Rua Duarte de Azevedo, 284, s 22, São Paulo, SP, Brazil • 02036-021 E-mail: jgcluz@usp.br

- Received May 9, 2017 • Accepted June 7, 2017

- Dol http://dx.doi.org/10.11606/issn.2357-8041.clrd.2017..132015 


\section{INTRODUCTION}

Transverse maxillary deficiency is a relatively frequent alteration that may affect both adolescents and adults. It may be considered relative when there is dental discrepancy, and absolute when the deficiency affects the bone. In bone discrepancies greater than $5 \mathrm{~mm}$ in patients that have already reached bone maturity, it is difficult for isolated orthopedic forces to separate the maxilla, leading to dental inclinations and little bone expansion. ${ }^{1}$ The result is a relapse even with overcorrection, pain, gingival recession, compression of the periodontal ligament, and malocclusion. Therefore, aiming to avoid these complications, surgically assisted maxillary expansion becomes necessary. ${ }^{2}$

There are various types of distractor devices that may be used concomitantly when performing surgically assisted maxillary expansion. The most common types are: a) tooth-mucosa-supported or Haas appliance, b) tooth-supported or Hyrax appliance, and c) bone-to-bone or palatal distractor. The tooth-mucosa-supported or Haas appliance has an acrylic part in contact with the palatine mucosa, through which it distributes the expansion forces among the posterior teeth and palate. The toothsupported or Hyrax appliance does not have the resin part in contact with the palatine mucosa; it transmits the expansion force in the maxilla through the supported teeth. Although there is no consensus in the literature about the mode of action of these appliances, the Hyrax appliance has the advantage of being easy to clean, comfortable and preserving the palatine mucosa in comparison with the Haas appliance. On the other hand, dental anchorage leads to innumerable complications including damage to the teeth, anchorage loss, periodontal pockets, and root resorptions, among others. ${ }^{2}$

Some types of distractors have been developed to avoid these dental complications. This distractor is placed directly onto the palatine bone during surgery. The main advantage is that the mechanical forces act directly on the bone in the desired area, thereby avoiding dental inclinations or undesirable movements of the maxillary segments, as well as causing no damage to the periodontium. As disadvantages of this type of appliance, the authors may cite the high cost, risk of lesions to dental roots during placement of the screw, risk of loss of the screw and the need to remove the appliance under local anesthetic after the period of bone consolidation. $^{2-4}$

In the current literature, there are innumerable studies describing the use of surgically assisted maxillary expansion to treat bilateral transverse discrepancies. However, little or nothing has been described about the treatment of unilateral maxillary discrepancy without association of cleft palates.

The aim of this article is to present a clinical case of treatment for unilateral maxillary discrepancy associated with an impacted maxillary left canine. It was performed using unilateral subtotal LeFort I osteotomy and intermaxillary suture with a palatal distractor and traction of the impacted maxillary left canine.

\section{CASE REPORT}

The 23-year-old male patient was referred for orthopedic surgical treatment of malocclusion by the orthodontist. He had a unilateral posterior crossbite on the left side and skeletal Class I malocclusion, associated with an impacted maxillary left canine observed by clinical and imaging evaluation (Figures 1, 2 and 3). The patient had no syndrome or clinical alteration.

In this case, due to the patient's age, the median palatine suture was consolidated. Therefore, the option on the left side was to perform a unilateral surgically assisted maxillary expansion to increase the space in the maxillary arch, aiming to correct the posterior crossbite and traction of the impacted maxillary left canine, thereby preserving the good occlusion on the right side. 


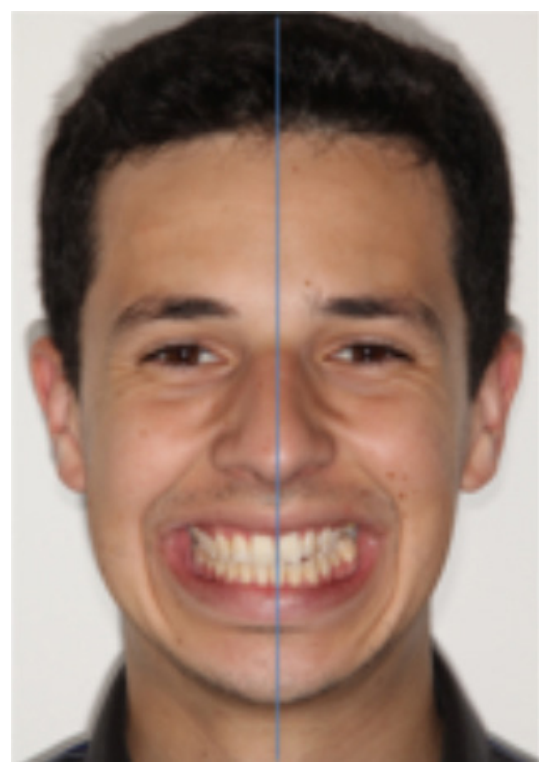

Figure 1 | Facial analysis.

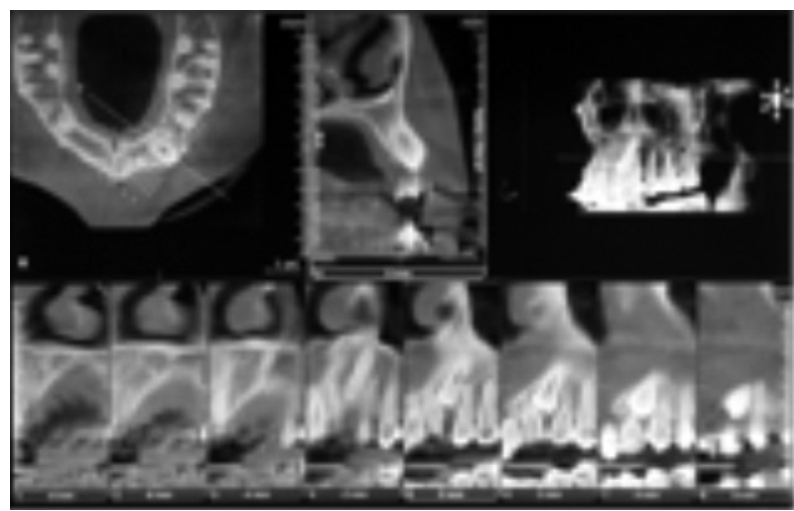

Figure 2 | Computed tomography.

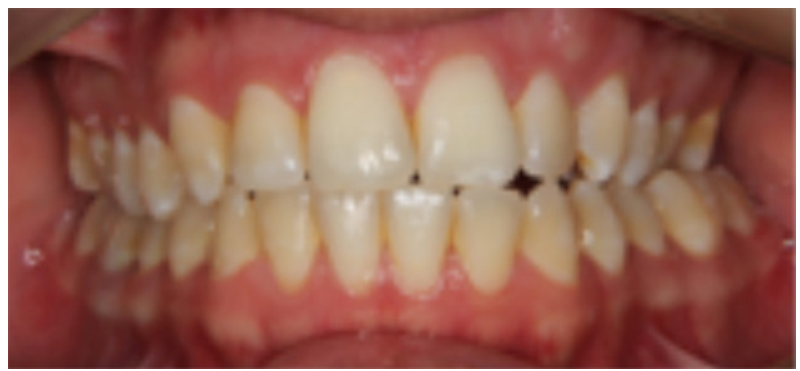

Figure 3 | Occlusal analysis.

The surgical procedure was held under general anesthesia. The surgical technique used was the one described by Bell and Epker (1976), however, with some modifications for the left side. The maxilla was exposed after a straight-line incision in the oral mucosa, muscles and periosteum. A horizontal osteotomy was performed on the lateral wall of the maxilla from the pyriform aperture to the maxillaryzygomatic pillar, $5 \mathrm{~mm}$ above the dental apices on the left side. For this purpose, a reciprocating saw and a No.703 bur (MicroAire ${ }^{\circledR}$ Charlottesville, Virginia) were used in the zygomatic pillar region to avoid possible interferences. Subsequently, a vertical osteotomy was performed, starting from the anterior nasal spine up to the alveolar crest adjacent to the maxillary central incisors, using a piezosurgery motor (Mectron $^{\circledR}$ Carasco, Italy). The pterygomaxillary fissure was separated with the aid of a curved chisel (W Lorenz Inc. ${ }^{\circledR}$ Florida, US) (Figure 4).

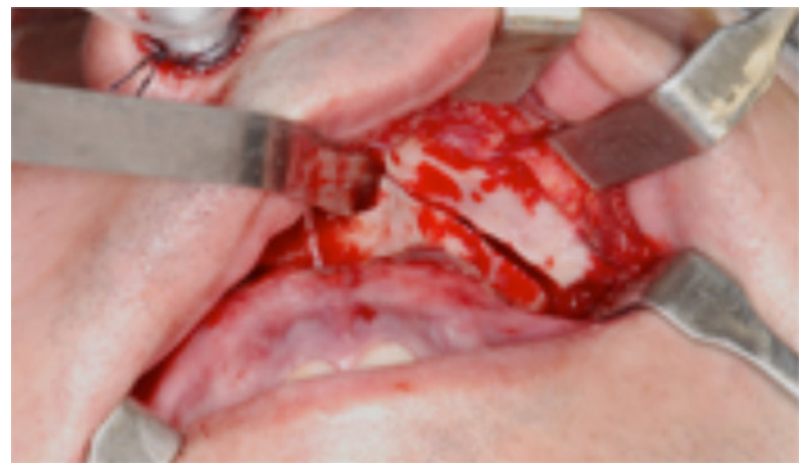

Figure 4 | Unilateral subtotal LeFort I osteotomy.

After the osteotomies were performed, the 18-mm RPE palatal distractor (KLS Martin ${ }^{\circledR}$ Freiburg, Germany) was adapted to the palatine bone in the region adjacent to the 1st molar and 2nd premolars, and fixed with one 7-mm titanium screw (KLS Martin ${ }^{\circledR}$ Freiburg, Germany) on each side. The distractor was activated in the intraoperative period until the opening between the incisors was verified, and closed back into its initial position. The alar base cinch suture was made with 2-o nylon (Ethicon ${ }^{\circledR}$ Johnson \& Johnson Company. São José dos Campos, Brazil) and the oral mucosa suture, with 4-o vicryl (Ethicon ${ }^{\circledR}$ Johnson \& Johnson Company. São José dos Campos, Brazil). A latency period of 7 days 
was awaited before beginning with activation of the distractor at a daily rate of $1.00 \mathrm{~mm}(0.33 \mathrm{~mm}$ 3 times per day) for 12 days.

The first activation was conducted in the dental office and the patient was instructed to activate the distractor. After achieving the desired amount of unilateral expansion, the palatal distractor was locked and left in this position for 4 months, waiting for bone repair. Moreover, in the 3 rd postoperative month, all orthodontic appliances were inserted to begin the orthodontic treatment (Figures 5 and 6). After 4 months, the palatal distractor was removed in a surgical procedure with local anesthesia.

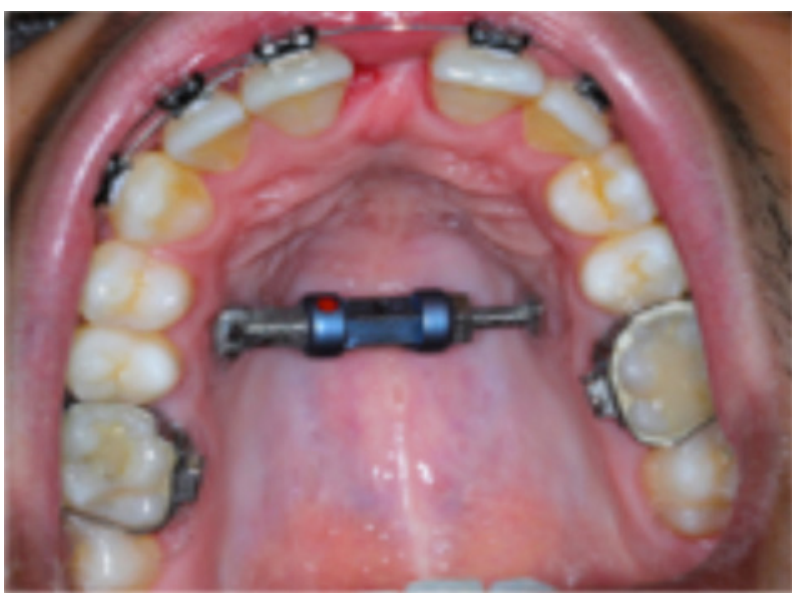

Figure 5 | Postoperative period at 3 months.

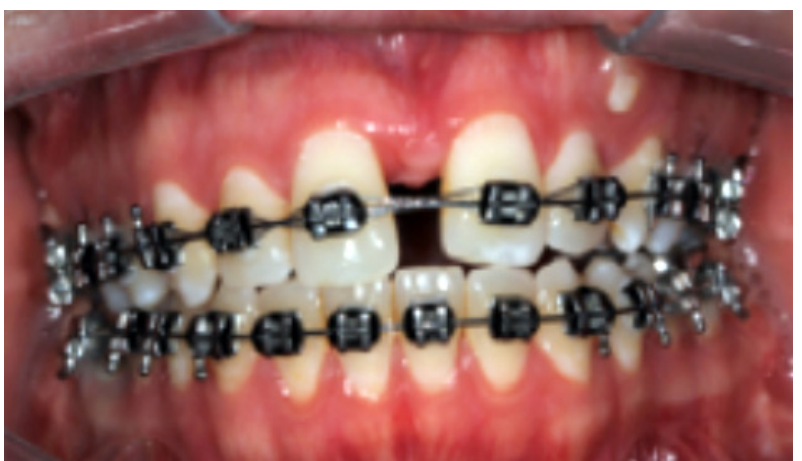

Figure 6 || Postoperative period at 3 months.

The impacted canine was included in the arch by orthodontic traction, using a gold-plated chain (Morelli Ortodontia ${ }^{\circledR}$ Sorocaba, Brazil) bonded to the canine crown with resin composite, and fixed to the orthodontic archwire of the maxilla. This procedure was performed 4 months after the unilateral maxillary expansion surgery, with the palatal distractor still in position. The teeth were aligned and leveled in 14 months. The patient showed no dental problem or anchorage loss of the appliance; furthermore, he reported no discomfort during the period of palatal distractor activation. After 20 months, the patient showed an excellent Class I occlusion and the orthodontic appliances were removed (Figure 7).

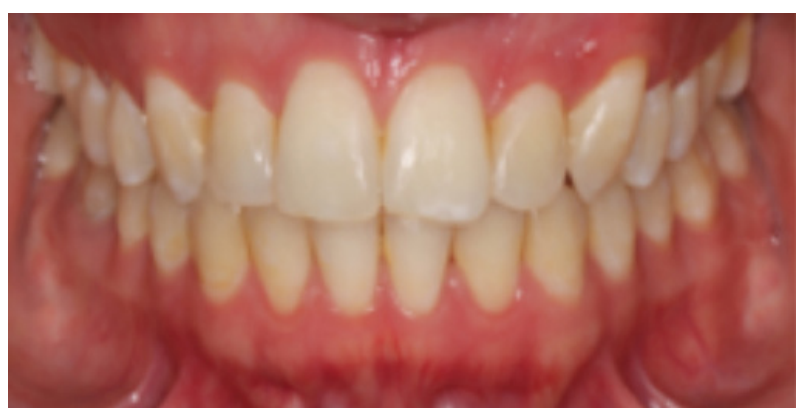

Figure 7 | Postoperative period at 20 months.

\section{DISCUSSION}

Transverse maxillary discrepancy is frequently observed in adolescent and adult patients. In most cases, they are associated with an anteroposterior or vertical alteration, in both Class II or Class III patients. ${ }^{6}$ This alteration generally occurs bilaterally; however, when it occurs unilaterally, it is frequently associated with cleft palates. Currently, there are no reports in the literature on performing unilateral surgically assisted maxillary expansion to correct malocclusions. Once bone maturity has been reached, an isolated orthodontic treatment is unable to promote a stable expansion of the maxillary atresia in deficiencies exceeding 5 mm. ${ }^{1}$ After introduction of the bone distraction theory, the combination of orthodontic surgical treatment for maxillary expansion in patients 
with bone maturity have been developed with variations of the surgical technique, ${ }^{5-7}$ with the same objective: to break bone resistance to facilitate the maxillary expansion process with the least amount of morbidity possible.

Impaction of the maxillary canines occurs more frequently due to their long and complex eruption pathway, with formation lateral to the pyriform aperture up to their final position of eruption. On average, it occurs from 0.27 to 2.4 $\%$ of the population, affecting more people of the female gender, erupting on the palatine side in most cases. Among the general etiological factors, studies have found local obstructions, local pathologies, developmental disturbances and genetic factors. There are two possibilities that justify orthodontic treatment: improvement in dental alignment and dental occlusion; and facial harmony and aesthetics. ${ }^{8}$ In this clinical case, the patient was a young man, with a skeletal Class I malocclusion with unilateral posterior transverse discrepancy, associated with an impacted maxillary left canine from the vestibular side, with no relation to any syndrome. On the right side, he had good occlusion with a good molar and canine relationship; therefore, the option was to perform unilateral osteotomy to maintain the good occlusion on the right side and promote expansion of the maxillary segment only on the left side, making use of the impacted canine.

To avoid complications, such as damage to the periodontium, root resorptions, undesirable dental inclinations and particularly, to prevent bilateral expansion, the Rotterdam palatal distractor (KLS Martin) was used. This was activated only on the left side, where the posterior crossbite was observed; the right side was locked to serve as resistance to undesirable expansion. In addition, the palatal distractor is easier to clean and facilitates the movement of the tongue, not interfering in phonation of words and feeding.
It has been described that a relapse occurs in the canine regions, having less incidence in the molar regions with the use of distractors with dental anchorage. In a systematic review conducted by Verstraaten et al. (2010), on distractors with bone anchorage, the authors concluded that distractors with bone anchorage promoted significantly less dental inclination than the traditional distractors with dental anchorage, with this being a precondition for postoperative stability.

The frequency of activation and its influence on the expanded tissues performed in rats were studied by Ilizarov (1989). He observed that an activation of $0.5 \mathrm{~mm}$ per day resulted in premature bone consolidation, making it difficult to achieve the desired bone distraction. When performing activations of $2 \mathrm{~mm}$ per day, the author observed damage to the soft tissue and formation of pseudarthrosis. The best result for soft tissue (periosteum, vessels, nerves, muscles) and bone was obtained with a rate of $1 \mathrm{~mm}$, at a frequency of four times per day (0.25 mm per activation). The amount of expansion performed in our study was obtained in 12 days, with 3 daily activations (0.33 $\mathrm{mm} \mathrm{x} \mathrm{3)} \mathrm{being} \mathrm{performed} \mathrm{until} \mathrm{the} 12 \mathrm{~mm}$ of expansion were attained. During this process, the patient reported no painful complaints, and the authors observed no postoperative complications.

\section{CONCLUSION}

The unilateral surgically assisted maxillary expansion, performed with the aid of the palatal distractor, was shown to be efficient in the treatment of unilateral transverse maxillary deficiency to facilitate the use of the impacted maxillary canine with reduced morbidity, higher rates of acceptance and to preserve the good occlusion on the opposite side.

This research received no specific grants from funding agencies in the public, commercial, or nonprofit sectors. 


\section{REFERENCES}

1. Silverstein K, Quinn PD. Surgically-assisted rapid palatal expansion for management of transverse maxillary deficiency. J Oral Maxillofac Surg. 1997 Jul;55(7):725-7.

2. Chrcanovic BR, Custódio AL. Orthodontic or surgically assisted rapid maxillary expansion. Oral Maxillofac Surg. 2009 Sep;13(3):123-37.

3. Dergin G, Aktop S, Varol A, Ugurlu F, Garip H. Complications related to surgically assisted rapid palatal expansion. Oral Surg Oral Med Oral Pathol Oral Radiol. 2015 Jun;119(6):601-7.

4. Koudstaal MJ, Wolvius EB, Schulten AJ, Hop WC, van der Wal KG. Stability, tipping and relapse of bone-borne versus tooth-borne surgically assisted rapid maxillary expansion; a prospective randomized patient trial. Int J Oral Maxillofac Surg. 2009 Apr;38(4):308-15.

5. Bell WH, Epker BN. Surgical-orthodontic expansion of the maxilla. Am J Orthod. 1976 Nov;70(5):517-28.
6. Wolford LM, Rieche-Fischel O, Mehra P. Soft tissue healing after parasagittal palatal incisions in segmental maxillary surgery: a review of 311 patients. J Oral Maxillofac Surg. 2002 Jan;60(1):20-5.

7. Rana M, Gellrich N-C, Rana M, Piffkó J, Kater W. Evaluation of surgically assisted rapid maxillary expansion with piezosurgery versus oscillating saw and chisel osteotomy: a randomized prospective trial. Trials. 2013 Dec;14:49.

8. Becker A, Chaushu S. Etiology of maxillary canine impaction: a review. Am J Orthod Dentofacial Orthop. 2015 Oct;148(4):557-67.

9. Verstraaten J, Kuijpers-Jagtman AM, Mommaerts MY, Bergé SJ, Nada RM, Schols JG. A systematic review of the effects of bone-borne surgical assisted rapid maxillary expansion. J Craniomaxillofac Surg. 2010 Apr;38(3):166-74.

10. Ilizarov GA. The tension-stress effect on the genesis and growth of tissues: part II. The influence of rate and frequency of distraction. Clin Orthop Relat Res. 1989 Feb;(239):263-85. 